\title{
Renal disease in patients infected with hepatitis B virus
}

\author{
Ajay Jaryal, Vivek Kumar, Vishal Sharma ${ }^{1}$
}

ABSTRACT

Department of Nephrology and Gastroenterology ${ }^{1}$,

Postgraduate Institute of Medical Education and Research,

Chandigarh, India-160012

\section{Correspondence:}

Dr. Vishal Sharma

Email: docvishalsharma@gmail.com
Infection with hepatitis B virus (HBV) can result in hepatic diseases which may include an asymptomatic non-replicative carrier state, immunotolerant phase characterized by high DNA levels without significant hepatic injury, immune-reactive phase characterized by occurrence of chronic hepatitis and fibrosis in the liver, or complications like cirrhosis or hepatocellular carcinoma. Extrahepatic manifestations may also accompany HBV infection. These may include serum sickness syndrome, polyarthralgia, polyarthritis, dermatologic manifestations like pitted keratolysis, urticaria, purpura, oral lichen planus or Gianotti-Crosti syndrome-a childhood papular eruption. Renal involvement may occur with HBV infection and usually involves glomerular or vascular injury. Various morphologic forms of renal injury have been reported with HBV infection, the commonest being membranous glomerulonephritis. The manifestations may include swelling over face and body, pedal edema, and urinary abnormalities. Evaluation may detect proteinuria, hematuria and reduction in estimated glomerular filtration rate (GFR). The management options include use of antiviral drugs targeting HBV infection with or without concomitant immunosuppressive medication. With availability of newer drugs like entecavir and tenofovir, these have become the first line agents as they have a high barrier to resistance. Sole use of immunosuppression is not recommended for lack of clear benefit and the possible risk of $\mathrm{HBV}$ reactivation or flare.

KEYWORDS: Hepatitis B; acute kidney injury; liver cirrhosis; glomerulonephritis; membranous glomerulonephritis, membranoproliferative glomerulonephritis, IgA nephropathy; antiviral agents; immunosuppressive agents; chronic hepatitis.

\section{Introduction}

Globally, the burden of infectious diseases remains high because of a large population at risk and poor health care infrastructure especially in resource constrained settings. Though morbidity and mortality associated with infectious diseases are usually in the form of a one time acute illness, some infections lead to a chronic disease state with a significant morbidity related to direct or indirect secondary involvement of various organ systems. Hepatitis B virus (HBV) infection is one such infection caused by HBV, which is an enveloped deoxyribonucleic acid (DNA) virus belonging to the Hepadnaviridae family. ${ }^{1}$

World Health Organization (WHO) identifies HBV infection as a major global health concern. ${ }^{[2]}$ Despite the presence of an effective vaccine for almost 30 years now, a significant proportion of the world population is chronically infected with HBV. WHO estimates suggest that approximately 240 million persons are chronically infected with $\mathrm{HBV}^{2}$ The prevalence of chronic HBV infection based on HBV surface antigen (HBsAg) 
seroprevalence data varies widely and ranges from $<2 \%$ in North America and Western Europe to $>8 \%$ in West SubSaharan Africa. ${ }^{3}$ Over the last three decades, the prevalence of HBV infection has decreased worldwide but the absolute number of persons with chronic HBV infection has increased on account of the expanding population. ${ }^{3}$ The prevalence in males has been reported as slightly higher than in females (3.9\% in males versus $3.5 \%$ in females) with an overall prevalence of 3.7\% ${ }^{[3]}$ The Global Burden of Disease Study 2013 identifies HBV infection as a prominent cause of mortality due to hepatitis, cirrhosis of the liver and liver cancer. ${ }^{4}$ Annually, 686,000 die as a result of direct or indirect consequences of HBV infection. Cirrhosis and liver cancer secondary to chronic HBV infection account for $90 \%$ of this mortality whereas acute viral hepatitis due to $\mathrm{HBV}$ infection accounts for the remaining $10 \%$ cases. $^{4}$

HBV infection usually affects the liver and depending on the status of viral replication, liver enzymes and hepatic necrosis and fibrosis, various phases have been described. Briefly, the immunotolerant phase is characterized by high viral load with active replication and $\mathrm{HBeAg}$ positivity with normal liver enzymes. Immune reactive phase is characterized by elevations in liver enzymes and occurrence of hepatic necrosis and fibrosis. This is often labeled as chronic hepatitis and may be $\mathrm{HBeAg}$ positive or negative. Repeated bouts of activity accelerate fibrogenesis and may result in cirrhosis. Occurrence of hepatocellular carcinoma can occur with HBV infection both in the presence or absence of cirrhosis. Some patients are able to clear the infection from the blood with loss of HBeAg and seroconversion to Anti-HBe positivity with low or undetectable DNA levels and are termed as non-replicative carriers. ${ }^{5} \mathrm{HBV}$ infection has also been associated with various extra-hepatic manifestations. ${ }^{6,7}$ The actual incidence of extra-hepatic manifestations, including renal involvement, in HBV infection seems to be low but this rarity does not, in any way, take away the significance of these manifestations. Their prompt identification is important because of significant morbidity and variable response to therapy. Though the exact mechanism is not known, it is believed that immunologic response mounted by the host against the infection plays an important role. It is important to remember that extra-hepatic manifestations in HBV infection are non-specific and may be seen with other diseases as well. Renal involvement secondary to HBV infection is closely linked to epidemiology of $\mathrm{HBV}$ infection, the pediatric population is affected more in endemic regions where transmission is mostly vertical whereas adult population is predominantly affected in regions where sporadic transmission occurs through infected blood, blood products or body fluids. Renal manifestations in HBV infection are mainly due to glomerular or vascular involvement, and can be acute or chronic. Globally, HBV infection is presumed to be the most common cause of viral nephropathy.

\section{Mechanisms and pathology of renal involvement in HBV infection}

Broadly, renal involvement in any disease whether it is primary (i.e. diseases primarily involving the kidneys) or secondary (i.e. diseases primarily involving other organ systems with secondary involvement of kidneys) can be thought of as involvement of one of the three functional areas of the kidney i.e. glomerular, tubulo-interstitial or vascular compartments. Though urinary tract that drains the urine produced by the kidneys can also be involved in some diseases affecting the kidneys e.g. diabetes mellitus that can lead to both diabetic glomerulosclerosis and diabetic cystopathy, manifestations arising out of urinary tract involvement are usually considered separately as genitourinary manifestations. If we consider renal involvement in $\mathrm{HBV}$ infection according to this conceptual framework, evidence suggests that renal manifestations are mainly due to glomerular or vascular (renal ischemia due to direct involvement of renal vessels) involvement.

Usually, renal dysfunction in viral infections is either a result of direct or indirect cytopathic effects of infecting virus on host cells, or a fallout of the immune response mounted by the host immune system against the infecting organism. ${ }^{8}$ In addition, effects of sepsis or shock secondary to infection and drug related nephrotoxicity might also lead to renal dysfunction in viral infections.Though not completely understood, renal involvement in $\mathrm{HBV}$ infection is not likely due to any direct or indirect cytopathic effect of HBV. It is believed that circulating immune complex deposition or in situ immune complex formation in glomeruli and subsequent complement activation leads to damage that manifests as various forms of glomerulonephritis, membranous pattern being most common amongst them..$^{8-11}$ Other major morphologic patterns of glomerular injury include membranoproliferative glomerulonephritis and IgA nephropathy. ${ }^{10}$ When similar processes occurs in medium sized vessels, theygives rise to HBV associated poly arteritis nodosa.

The clinical presentation in HBV infection is a complex interplay of several viral and host specific factors which can 
possibly explain the inter-individual differences, but has still not been accurately described. ${ }^{12}$ It is believed that the development of an effective cytolytic $\mathrm{T}$ cell response in acute $\mathrm{HBV}$ infection is responsible for recovery from the infection. ${ }^{12}$ A subnormal or depressed cytolytic $\mathrm{T}$ cell response may be responsible for the development of a chronic carrier state, the course of which may be interrupted by subclinical or clinically apparent viral activity. It has been postulated that inadequate cellular immune response against HBV infection may lead to persistence of antigenic stimulation and subsequent continuous antibody production that may lead to the development of immune complex mediated glomerular injury. ${ }^{13}$ The morphologic classification of glomerular injury in HBVrelated glomerulonephritis depends on the site and type of immune complex deposition and resulting injury pattern. When immune complexes are predominantly present in the subepithelial region of glomeruli and result in stiff and thick appearance of capillary loops with predominance of immunoglobulin $\mathrm{G}(\mathrm{IgG})$ and complement component $\mathrm{C} 3$ on immunofluorescence, the pattern is referred to as membranous pattern. Membranous nephropathy is the most common pattern of injury in HBV-related renal disease. It is important to note that mesangial hypercellularity, endocapillary proliferation, subendothelial deposits, mesangial deposits, and presence of other immunoglobulins like immunoglobulin $\mathrm{M}(\operatorname{IgM})$, immunoglobulin $\mathrm{A}(\operatorname{Ig} \mathrm{A})$ and complement component $\mathrm{C} 1$ is more common in HBV-related membranous nephropathy than primary membranous nephropathy, which, in fact, is true for other forms of secondary membranous nephropathy as well. ${ }^{14,15}$ When glomerular involvement is in the form of predominant mesangial hypercellularity or proliferation with interposition of mesangium in the subendothelial space leading to double contour of glomerular basement membrane, mesangial immune complex deposits, subendothelial immune complex deposits and presence of variable immunoglobulins and complement components, the pattern is referred to as membranoproliferative type 1 pattern. When subepithelial deposits also accompany predominant membranoproliferative type 1 pattern, it is referred to as membranoproliferative type 3 pattern. It is important to note that membranoproliferative pattern should be due to dominant immune complex deposition and not complement components in HBV-related membranoproliferative glomerulonephritis. Similarly, when the immunofluorescence examination suggests dominant immunoglobulin A deposition, glomerular involvement is designated as immunoglobulin A nephropathy. Therefore, immune complex deposition mediated injury seems central to the pathogenesis of HBV-related glomerular involvement, and the various forms defined are just a reflection of site and type of immunoglobulin deposited and resulting glomerular injury pattern.

$\mathrm{HBV}$ infection is characterized by the presence of various antigens i.e. $\mathrm{HBV}$ surface antigen (HBsAg), and HBV envelope antigen ( $\mathrm{HBeAg}$ ) or antibodies (anti $\mathrm{HBe}$ and also antibody to the $\mathrm{HBV}$ core antigen i.e. anti $\mathrm{HBc}$ ) or $\mathrm{HBV}$ deoxyribonucleic acid (DNA) in blood depending on the phase and host response to infection. In patients demonstrating serum markers of HBV infection and unrelated renal diseases, it has been shown that it was not unusual to find $\mathrm{HBV}$ antigens on staining of renal tissues. ${ }^{16}$ However, the mere presence of antigens or demonstration of HBV genetic material inside host kidney cells, even in patients presumed to have HBV-related glomerular disease, is not sufficient to induce damage. It has been shown by experimental studies in mice, with immune complex glomerulonephritis, that the concentration and avidity of antibodies for antigens may be important determinants of site of immune complex deposition. ${ }^{17}$ Studies in both children and adults suggest that $\mathrm{HBeAg}$-related immune complex deposition is central to HBV-related membranous nephropathy. ${ }^{18-20}$ The presence of $\mathrm{HBeAg}$ in immune complexes during active disease with proteinuria, resolution of proteinuria with development of anti $\mathrm{HBe}$ antibody and disappearance of $\mathrm{HBeAg}$, and lack of consistent demonstration of $\mathrm{HBsAg}$ or $\mathrm{HBcAg}$ in immune complexes in patients with symptomatic renal involvement point towards a possible pathogenetic role for $\mathrm{HBe} \mathrm{Ag}$ in $\mathrm{HBV}$ related membranous nephropathy. ${ }^{18-22}$ However, a recent report of HBsAg related glomerular immune complex deposition in membranous pattern in patients with presence of anti HBs antibodies but otherwise negative $\mathrm{HBsAg}$ and $\mathrm{HBeAg}$ in serum contests the notion that $\mathrm{HBsAg}$ may have no pathogenetic role. ${ }^{23}$ Similarly, demonstration of $\mathrm{HBsAg}$ or $\mathrm{HBcAg}$ in renal biopsy tissue of $1.8 \%$ ( 9 out of 500 patient samples) patients with glomerulonephritis with no serological evidence of HBV infection seems intriguing. ${ }^{24}$ In one report of IgA nephropathy secondary to HBV infection, $40 \%$ patients had trapping of HBsAg in mesangium by polyclonal immunoglobulin staining. ${ }^{25}$ However, we must note that such reports do not conclusively establish their role. Rare associations of HBV infection with minimal change disease and cryoglobulinemic glomerulonephritis have also been reported. ${ }^{26,27}$

Gene expression profiling in transgenic mice suggests that genes encoding for complement pathway, acute phase responses and coagulation pathways are significantly 
upregulated in renal tubular epithelial cells after HBV infection. ${ }^{28}$ Whether these hold true for humans also, is still not known. There may be an impact of viral genotype on development of HBV-related glomerular involvement. In a series of six patients with $\mathrm{HBV}$-associated nephropathy from Japan, genotype A was found to be dominant in contrast to genotype $\mathrm{C}$ that was otherwise dominant in Japanese chronic hepatitis patients. ${ }^{29,30}$ However, in a study of 296 pediatric patients with HBV infection in China with somewhat limited genotype data, the representation of genotype $\mathrm{C}$ was significantly higher compared to genotype $\mathrm{B}$ in patients with $\mathrm{HBV}$ related glomerular involvement. ${ }^{31}$ Similarly, HLA associations with susceptibility to develop various manifestations or outcomes in HBV infection have also been investigated. ${ }^{32-36}$ Studies in black children and Polish children with HBV associated membranous nephropathy have suggested association of HLA DQB $1 * 0603$ and DQB $1 * 0303$, respectively, with the disease. ${ }^{37,38}$ However, the exact significance of these genetic differences are not known and can be an area of active investigation.

As membranous nephropathy is the most common form of glomerular morphology seen in HBV-related glomerular disease and discovery of anti $\mathrm{M}$ type phospholipase A2 receptor antibody has significantly uncovered the understanding of pathogenesis of so called idiopathic or primary membranous nephropathy, it would be interesting to see whether this antibody will be able to differentiate between primary membranous nephropathy with incidental detection of viral antigens from true secondary form of membranous nephropathy related to $\mathrm{HBV}$ infection. ${ }^{39} \mathrm{In}$ a study from China, standard Western Blot assay detected these antibodies in only 1 out of 20 patients with HBV-related membranous nephropathy. ${ }^{40}$

Though very rare nowadays, $\mathrm{HBV}$ infection associated poly arteritis nodosa (PAN) is another HBV-related extra-hepatic manifestation which can involve the kidneys. ${ }^{41}$ PAN is focal, transmural, necrotizing inflammation involving the mediumsized arteries. Involvement of renal arteries, mainly interlobar and arcuate arteries, may lead to development of arterial aneurysms, thrombosis, renal infarction or hemorrhage. Direct vascular damage as suggested by actively replicating organism in involved vessels and immune-complex deposition followed by complement activation mediated vascular damage are two mechanisms that have been proposed to account for this manifestation. ${ }^{42}$ Though current observations do not confirm pathogenic role of organism, the unusually high occurrence rate of almost 1000 times for PAN in HBV infected individuals as compared to general population and clinical response to antiviral therapy and plasmapheresis, indirectly suggest strong association. ${ }^{43,44}$ In fact, the presence of HBV infection is one of the American College of Rheumatology classification criteria for PAN. ${ }^{45}$

\section{Diagnosis}

Urinalysis, serum creatinine and imaging of the urinary tract mainly by ultrasonography are the mainstays of preliminary diagnosis of various forms of primary and secondary renal involvement in different diseases. In general, the definitive diagnosis of a majority of acute kidney diseases can be established only by a renal biopsy, though a renal biopsy may not be warranted in every clinical situation. Whenever a patient has abnormal urinalysis or decreased estimated glomerular filtration rate (eGFR) as reflected by elevated serum creatinine in the setting of HBV associated known liver disease (acute or chronic) or serum HBsAg positivity, he would be suspected to have HBV-related renal disease. As of now, all patients who come to medical attention with either acute kidney disease or chronic kidney disease (CKD) are routinely screened for $\mathrm{HBsAg}$ because HBV is considered an important secondary cause of acute kidney disease especially in endemic regions and HBV vaccination is an important part of management of CKD patients in view of them being at high risk of acquiring HBV infection because of high likelihood of receiving blood transfusions and need of hemodialysis in future.

Usually, proteinuria $>1 \mathrm{~g}$ /day or presence of microscopic or gross hematuria with presence of RBC casts on urinalysis suggests glomerular involvement. Asymptomatic urinary abnormalities (proteinuria, microscopic hematuria etc.), nephrotic syndrome, nephritic syndrome or rapidly progressive glomerulonephritis are the clinically recognized syndromes of glomerular involvement in acute kidney diseases. In fact, HBVrelated glomerular involvement is actually acute kidney disease and usually presents as nephrotic syndrome, nephritic syndrome or asymptomatic urinary abnormality. For definitive diagnosis of HBV-related glomerular involvement, renal biopsy is a must (Figure 1). At present, diagnosis is made when a renal morphological pattern consistent with HBV-related glomerular disease is found in conjunction with the presence of HBV in blood and without any other secondary cause for glomerular injury. ${ }^{46}$ In a series of 100 patients with primary glomerulonephritis and positive HBsAg in blood, only $39 \%$ of the biopsies stained with either one or more of $\mathrm{HBV}$ antigens 


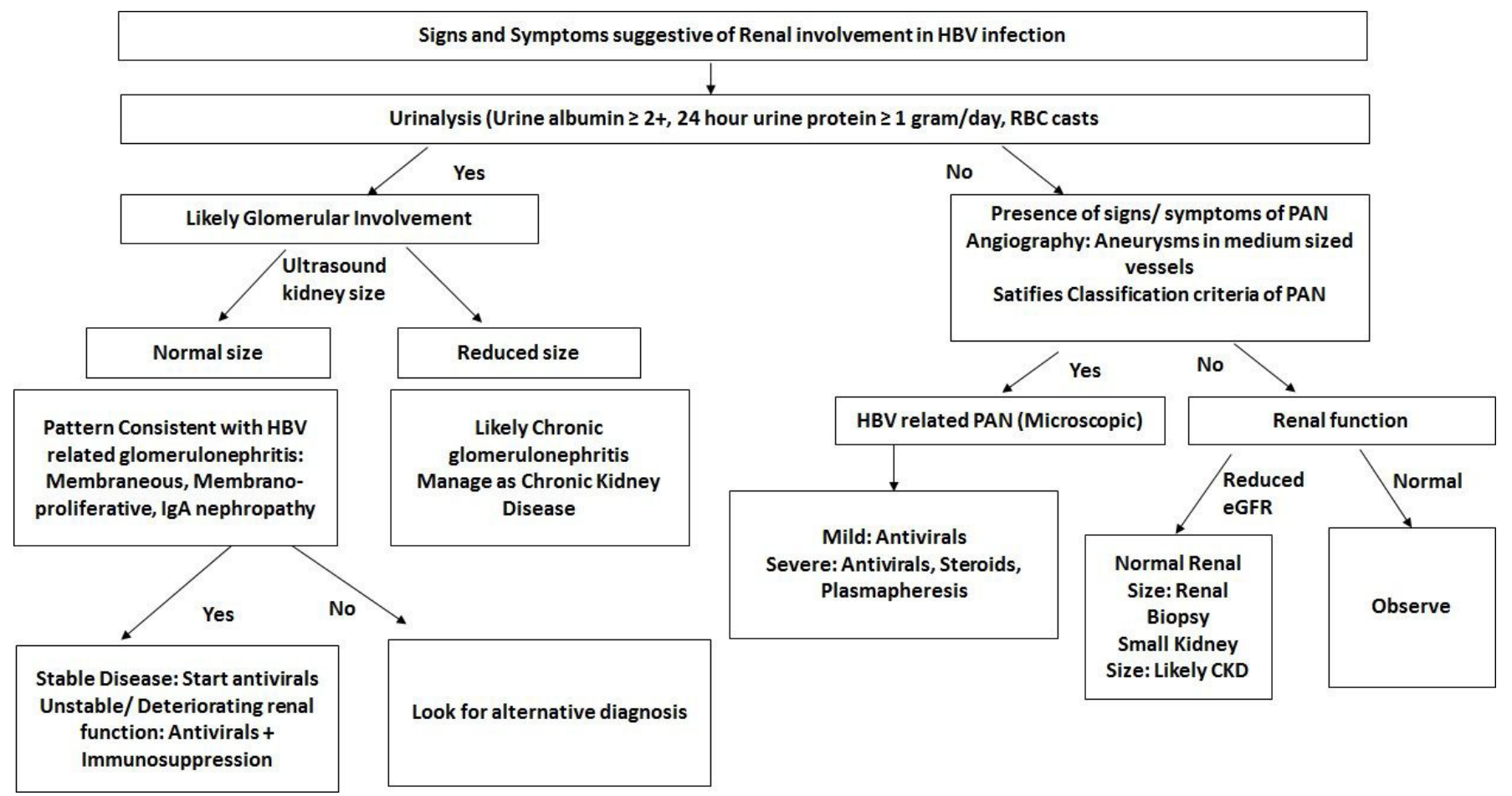

Figure 1: Approach to evaluation of renal involvement in HBV infection

(i.e. HBsAg, $\mathrm{HBeAg}$ or $\mathrm{HBcAg}$ ) by monoclonal antibodies. ${ }^{47}$ In this study, $\mathrm{HBeAg}$ or HbsAg staining in glomeruli was seen in $28.4 \%$ and $22.3 \%$ biopsies, respectively. ${ }^{47}$ Recently, glomerular staining with $\mathrm{HBsAg}$ in patients with negative HBsAg and positive anti HBs antibody in serum but with glomerular morphology consistent with HBV-related glomerular disease description has been reported. ${ }^{23}$ The HBV antigen staining on renal biopsies has been suggested but no universally accepted diagnostic criteria for HBV related glomerular disease exist because of current gaps in understanding of its pathogenesis and lack of standardization of laboratory staining techniques. ${ }^{23,48}$ It seems logical that a combination of immune complex glomerulonephritis without any other secondary cause together with evidence of HBV infection in blood and demonstration of HBV antigens or genetic material that co-localizes with site of injury in glomeruli would form strict diagnostic criteria that would need validation across different populations. ${ }^{48}$

The diagnosis of HBV related PAN is according to the classification criteria as proposed by the American College of Rheumatology. ${ }^{45}$ Usually, a compatible history with characteristic histological involvement or demonstration of medium-sized vessel damage on angiography would suffice to make diagnosis. It is important to note that not all the classification criteria may be present at one particular time in an individual patient. Therefore, it becomes important to have a high index of suspicion followed by meticulous monitoring of patient. Also, the temporal profile of evolution of different clinical manifestations in an individual patient is important. It is highly unlikely that HBV infection would be responsible for renal involvement in a patient if there were no evidence of past or present $\mathrm{HBV}$ infection.

\section{Clinical manifestations}

The signs and symptoms in patients with HBV-related renal involvement depend on the underlying type of renal involvement. It is not uncommon to pick up renal involvement on routine examination or investigations in otherwise asymptomatic patients. Glomerular involvement may manifest with development of edema, excessive frothing of urine, gross hematuria or uremia related symptoms arising because of decrease in GFR whereas HBV-related PAN may present with typical features of PAN reflecting multisystem involvement. Constitutional symptoms like fever and weight loss, musculoskeletal symptoms like arthritis, arthralgias, myalgias or muscle weakness; mononeuritis multiplex, dermatologic like live doreticularis, purpura etc., abdominal pain due to visceral ischemia or hemorrhage including renal involvement and hypertension due to renal ischemia are prominent 
manifestations in PAN. Overall, renal involvement has been reported in 11-66\% of patients with PAN. ${ }^{49,50}$

Though fall in GFR at presentation would be more concordant with a diagnosis of membranoproliferative or mesangioprolifeartive pattern of involvement, morphology of glomerular injury cannot be ascertained without renal biopsy. There are important differences in clinical course of HBV-related membranous nephropathy seen between children and adults. Children are usually affected in endemic areas, often lack preceding history of hepatitis like illness, and upto 30-60\% may achieve a spontaneous remission. On the contrary, adults will often have evidence of hepatitis and are more likely to progress to chronic renal failure with poor response to therapy. ${ }^{11}$

\section{Treatment}

Intuitively the therapy for HBV-related renal disease may include therapy targeted at the HBV infection, or targeting the renal disease or a combination of both these aspects. A metaanalysis of 11 trials suggested that anti-viral therapy has a better response vis-à-vis reduction in proteinuria and $\mathrm{HBeAg}$ clearance when compared to controls whilst the use of steroids alone did not seem to improve proteinuria. ${ }^{51}$ Also, immunosuppressive therapy without the use of antivirals may not be recommended as there is an associated concern of HBV reactivation. Another meta-analysis reported that combination of antivirals and immunosuppression led to significant improvement in proteinuria and serum albumin levels amongst patents with $\mathrm{HBV}$ related glomerular disease. ${ }^{10}$

In the meta-analysis on antiviral drugs the major histologic pattern was membranous glomerulopathy and the antivirals included interferon and lamivudine. The remission rates in proteinuria were higher in the antiviral group when compared with the controls suggesting that use of antivirals should be unequivocally recommended in these patients. ${ }^{10}$ Another metaanalysis based on the same data also provided similar results. ${ }^{52}$ However in absence of head-to-head comparisons it may not be prudent to suggest one antiviral over the other. While interferon provides an opportunity for a limited duration of therapy, it comes at the cost of serious side effects and the fact that it is an injectable agent. Oral antivirals are usually safe but the duration of therapy remains uncertain. If oral antivirals are used one may prefer entecavir or tenofovir as these drugs have a high genetic barrier to resistance. Tenofovir, by itself, is implicated in causation of renal injury due to renal tubular injury.
In the meta-analysis on use of combination of antiviral and immunosuppressive agents, significant improvements in proteinuria and serum albumin were reported without any adverse effect on hepatic functions although liver enzyme elevations were noted in some patients. ${ }^{10}$ Interestingly no change in DNA titers was noted with treatment but all three trials reporting HBV DNA titers included lamivudine as antiviral agent. One expects that with use of newer anti-viral agents the titers of HBV DNA should decline with treatment.

$\mathrm{HBV}$ reactivation is an important concern in patients with renal disease related to $\mathrm{HBV}$ infection as these patients may need immunosuppressive treatment for management of renal involvement. Fortunately, with the availability of potent antivirals this complication is now entirely preventable. In patients with hepatitis B infection use of various markers of infection may indicate the risk of re-activation of hepatitis B if immunosuppressive therapy is administered. The risk for patients with HBsAg positive patients is higher than those who have only anti-HBc antibody positivity. Similarly presence of anti-HBs antibody may diminish but its presence or titres cannot be used to make decisions for or against the use of antiviral therapy. HBV DNA positivity as also $\mathrm{HBeAg}$ positivity certainly increases the risk of reactivation. The risk depends not only on the status of the underlying HBV infection but on the treatment regimen which is planned for the immune diseases. It is now apparent that therapies which deplete B cells (viz Rituximab) have high rates of viral reactivation followed by anthracycline, long term steroids, TNF-alpha inhibitors, and then traditional immunomodulators like azathioprine and methotrexate and low dose/short term (1 week) of steroids. Therefore it is prudent to test for HBsAg and anti-HBc prior to initiation of immunosuppressive therapy and if any of these markers is positive to further stratify the risk by doing markers like HBeAg, HBV DNA and anti-HBs apart from abdominal ultrasound. ${ }^{53,54}$ In patients with HBV-related kidney disease who are to receiveimmuno-modulatory or immunosuppressive therapy, use of drugs with high genetic barrier to resistance like entecavir and tenofovir is preferred to other drugs as some patients may be inherently resistant to lamivudine or may develop resistant strains while on therapy. The antivirals should ideally begin prior to initiation of immunosuppressive treatment and continue for 6 months after discontinuation of immunosuppression (12 months for B cell depleting agents). ${ }^{53}$, 54

All in all, a judicious approach in setting of HBV-related renal disease would be to initiate treatment with antiviral drugs 
alone (preferably entecavir or tenofovir) and to add immunosuppressive agents in case of worsening of renal function or lack of response. This will also provide time for the potent anti-viral drugs to control the HBV infection and avoid any $\mathrm{HBV}$ reactivation where immunosuppression is needed.

\section{Conclusions}

HBV infection is an important cause of morbidity and mortality across the world. Though there are measures available for its prevention and treatment, the magnitude of global burden of this disease is overwhelming and therefore, knowledge about its various manifestations assumes great significance. Renal involvement in $\mathrm{HBV}$ is seen in a minority of patients and is likely to occur in patients who remain infected. The fact that clinical involvement of liver may not be apparent in a large number of patients occasionally leads to delay in diagnosis if the clinical index of suspicion is not high, especially in endemic regions. There are no long-term, comprehensive registries of patients that have reported the manifestations and outcome of such patients. There are significant gaps in our understanding of its pathogenesis, and no universally accepted diagnostic criteria exist to define HBV-related renal involvement. Similarly, evidence for treatment of renal involvement in $\mathrm{HBV}$ is also not robust. It seems logical to first treat the $\mathrm{HBV}$ infection in case of stable and non-life threatening disease, and keep the patient on regular follow up. However, life threatening renal involvement in the form of rapidly progressive glomerulonephritis and severe form of PAN may necessitate addition of immunosuppressive drug treatment with or without plasmapheresis, as is done for similar forms of immune complex glomerulonephritis or idiopathic PAN. There is a strong need to develop long-term cohorts of patients with $\mathrm{HBV}$ infection so that a large evidence base is generated to plug the gaps in our knowledge and understanding. Similarly, the treatment issues need to be tested in large, adequately powered randomized controlled trials. As the epidemiology suggests different disease patterns in pediatric and adult populations, it is important to address these issues separately in both of them.

\section{References}

1. Ryan KJ, Ray CG. Hepatitis Viruses. Sherris Medical Microbiology, Sixth Edition. New York, NY, 2014

2, Organization WH. Hepatitis B. 2015

3. Ott JJ, Stevens GA, Groeger J, Wiersma ST. Global epidemiology of hepatitis B virus infection: new estimates of age-specific HBsAg seroprevalence and endemicity. Vaccine. 2012;30:2212-9.

4. Mortality GBD, Causes of Death C. Global, regional, and national age-sex specific all-cause and cause-specific mortality for 240 causes of death, 1990-2013: a systematic analysis for the Global Burden of Disease Study 2013. Lancet. 2015;385:117-71.

5. EASL clinical practice guidelines: Management of chronic hepatitis B virus infection.Journal of Hepatology.2012;57:167-85.

6. Czaja AJ, Carpenter HA, Santrach PJ, Moore SB. Immunologic features and HLA associations in chronic viral hepatitis. Gastroenterology.1995;108:157-64.

7. Pyrsopoulos NT, Reddy KR. Extrahepatic manifestations of chronic viral hepatitis. Current Gastroenterology Reports. 2001;3:71-8.

8. Lai AS, Lai KN. Viral nephropathy. Nat Clin Pract Nephrol. 2006;2:254-62

9. Chan TM. Hepatitis B and Renal Disease. Curr Hepat Rep. 2010;9:99-105.

10. Zheng XY, Wei RB, Tang L, Li P, Zheng XD. Meta-analysis of combined therapy for adult hepatitis B virus-associated glomerulonephritis. World J Gastroenterol. 2012;18:821-32

11. Bhimma R, Coovadia HM. Hepatitis B virus-associated nephropathy. Am J Nephrol. 2004;24:198-211

12. Dienstag JL. Acute Viral Hepatitis. In: Kasper D, Fauci A, Hauser S, Longo D, Jameson JL, Loscalzo J, editors. Harrison's Principles of Internal Medicine, 19e. New York, NY: McGraw-Hill Education, 2015

13. Lin CY, Lin CC, Chang GJ, King CC. Defect of cell-mediated immune response against hepatitis B virus: an indication for pathogenesis of hepatitis-B-virus-associated membranous nephropathy. Nephron.1997;76:176-85.

14. Li P, Wei RB, Tang L, Wu J, Zhang XG, Chen XM. Clinical and pathological analysis of hepatitis B virus-related membranous nephropathy and idiopathic membranous nephropathy. Clinical Nephrol. 2012;78:456-64.

15. Lai FM, To KF, Wang AY, Choi PC, Szeto CC, Li PK, et al. Hepatitis B virus-related nephropathy and lupus nephritis: morphologic similarities of two clinical entities. Mod Pathol. 2000;13:166-72

16. Chen L, Wu C, Fan X, Gao J, Yin H, Wang T, et al. Replication and infectivity of hepatitis $\mathrm{B}$ virus in HBV-related glomerulonephritis. Int J Infect Dis. 2009;13:394-8.

17. Germuth FG Jr, Rodriguez E, Lorelle CA, Trump EI, Milano LL, Wise O. Passive immune complex glomerulonephritis in mice: models for various lesions found in human disease. II. Low avidity complexes and diffuse proliferative glomerulonephritis with subepithelial deposits. Lab Invest.1979;41:366-71.

18. Hirose H, Udo K, Kojima M, Takahashi Y, Miyakawa Y, Miyamoto K, et al. Deposition of hepatitis B e antigen in membranous glomerulonephritis: identification by $\mathrm{F}\left(\mathrm{ab} \mathrm{b}^{\prime}\right) 2$ fragments of monoclonal antibody. Kidney Int 1984;26:338-41.

19. Ito H, Hattori S, Matusda I, Amamiya S, Hajikano H, Yoshizawa H, Miyakawa Y, Mayumi M. Hepatitis B e antigen-mediated membranous glomerulonephritis. Correlation of ultrastructural changes with $\mathrm{HBe} A \mathrm{~g}$ in the serum and glomeruli. $L a b$ Invest.1981;44:214-20. 
20. Lin CY. Hepatitis B virus-associated membraneous nephropathy: clinical features, immunological profiles and outcome. Nephron.1990;55:37-44.

21. Fabrizi F, Dixit V, Martin P. Meta-analysis: anti-viral therapy of hepatitis B virus-associated glomerulonephritis. Aliment Pharmacol Ther. 2006;24:781-8

22. Gilbert RD, Wiggelinkhuizen J. The clinical course of hepatitis B virus-associated nephropathy. Pediatr Nephrol.1994;8:11-4.

23. Li D, Gao G, Jiang H, Tang Z, Yu Y, Zang G. Hepatitis B virusassociated glomerulonephritis in HBsAg serological-negative patients. Eur J Gastroenterol Hepatol. 2015;27:65-9

24. Kong D, Wu D, Wang T, Li T, Xu S, Chen F, et al. Detection of viral antigens in renal tissue of glomerulonephritis patients without serological evidence of hepatitis B virus and hepatitis C virus infection. Int J Infect Dis. 2013;17:e535-538

25. Lai KN, Lai FM, Tam JS. Comparison of polyclonal and monoclonal antibodies in determination of glomerular deposits of hepatitis B virus antigens in hepatitis B virus-associated glomerulonephritides. Am J Clinical Pathol.1989;92:159-65

26. Enriquez R, Sirvent AE, Andrada E, Escolano C, Rodriguez JC, Millan I, et al. Cryoglobulinemic glomerulonephritis in chronic hepatitis B infection. Ren Fail. 2010;32:518-22.

27. Zhou TB, Jiang ZP. Is there an association of hepatitis B virus infection with minimal change disease of nephrotic syndrome? A clinical observational report. Ren Fail. 2015;37:459-61. [PMID: 25585950 DOI: 10.3109/0886022X.2014.1001711]

28. Ren J, Wang L, Chen Z, Ma ZM, Zhu HG, Yang DL, et al. Gene expression profile of transgenic mouse kidney reveals pathogenesis of hepatitis B virus associated nephropathy. J Med Virol. 2006;78:551-60.

29. Kusakabe A, Tanaka Y, Kurbanov F, Goto K, Tajiri H, Murakami $\mathrm{J}$, et al. Virological features of hepatitis B virus-associated nephropathy in Japan. J Med Virol. 2007;79:1305-11.

30. Orito E, Ichida T, Sakugawa H, Sata M, Horiike N, Hino K, Okita K, Okanoue T, Iino S, Tanaka E, Suzuki K, Watanabe H, Hige S, Mizokami M. Geographic distribution of hepatitis B virus (HBV) genotype in patients with chronic $\mathrm{HBV}$ infection in Japan. Hepatology. 2001;34:590-4.

31. Lei X, Gao X, Yang J, Sun Y, Sai Y, You W, et al. The genotype C could play a key role in hepatitis B virus associated nephritis among the northwest Chinese children. Eur J Intern Med. 2013;24:835-8

32. Thursz MR, Kwiatkowski D, Allsopp CE, Greenwood BM, Thomas HC, Hill AV. Association between an MHC class II allele and clearance of hepatitis B virus in the Gambia. N Eng J Med. 1995;332:1065-9.

33. Xi-Lin Z, Te D, Jun-Hong L, Liang-Ping L, Xin-Hui G, Ji-Rong $\mathrm{G}$, et al. Analysis of HLA-DQB1 gene polymorphisms in asymptomatic HBV carriers and chronic hepatitis B patients in the Chinese Han population. Intl J Immunogenet. 2006;33:249-54.

34. Kamatani Y, Wattanapokayakit S, Ochi H, Kawaguchi T, Takahashi A, Hosono N, et al. A genome-wide association study identifies variants in the HLA-DP locus associated with chronic hepatitis B in Asians. Nat Genet. 2009;41:591-5.

35. Höhler T, Gerken G, Notghi A, Lubjuhn R, Taheri H, Protzer U, et al. HLA-DRB $1 * 1301$ and $* 1302$ protect against chronic hepatitis B. J Hepatol. 1997;26:503-7.

36. Thio CL, Thomas DL, Karacki P, Gao X, Marti D, Kaslow RA, et al. Comprehensive analysis of class I and class II HLA antigens and chronic hepatitis $\mathrm{B}$ virus infection. $J$ Virol. 2003;77:12083-7.

37. Bhimma R, Hammond MG, Coovadia HM, Adhikari M, Connolly CA. HLA class I and II in black children with hepatitis B virusassociated membranous nephropathy. Kidney Intern. 2002;61:1510-5.

38. Vaughan RW, Zurowska A, Moszkowska G, Kondeatis E, Clark AG. HLA-DRB and -DQB1 alleles in Polish patients with hepatitis B associated membranous nephropathy. Tissue Antigens. 1998;52:130-4.

39. Du Y, Li J, He F, Lv Y, Liu W, Wu P, et al. The diagnosis accuracy of PLA2R-AB in the diagnosis of idiopathic membranous nephropathy: a meta-analysis.PloSOne.2014;9(8):e104936

40. Qin W, Beck LH, Zeng C, Chen Z, Li S, Zuo K, et al. AntiPhospholipase A2 Receptor Antibody in Membranous Nephropathy. JAM Soc Nephrol. 2011;22:1137-43.

41. Trépo C, Amiri M, Guillevin L. Extrahepatic Manifestations of Hepatitis B Infection. Viral Hepatitis: John Wiley \& Sons, Ltd, 2013:154-162

42. Mason A, Theal J, Bain V, Adams E, Perrillo R. Hepatitis B virus replication in damaged endothelial tissues of patients with extrahepatic disease. Am J Gastroenterol. 2005;100:972-6.

43. Guillevin L, Mahr A, Callard P, Godmer P, Pagnoux C, Leray E, et al. Hepatitis B virus-associated polyarteritisnodosa: clinical characteristics, outcome, and impact of treatment in 115 patients. Medicine. 2005;84:313-22.

44. Guillevin L, Lhote F, Leon A, Fauvelle F, Vivitski L, Trepo C. Treatment of polyarteritisnodosa related to hepatitis B virus with short term steroid therapy associated with antiviral agents and plasma exchanges. A prospective trial in 33 patients. $J$ Rheumatol. 1993;20:289-98.

45. Lightfoot RW, Jr., Michel BA, Bloch DA, Hunder GG, Zvaifler NJ, McShane DJ, Arend WP, Calabrese LH, Leavitt RY, Lie JT, et al. The American College of Rheumatology 1990 criteria for the classification of polyarteritisnodosa. Arthritis Rheum. 1990;33:1088-93.

46. Chapter 9: Infection-related glomerulonephritis. Kidney Inter, Suppl 2012;2:200-8.

47. Lai FM, Lai KN, Tam JS, Lui SF, To KF, Li PK. Primary glomerulonephritis with detectable glomerular hepatitis B virus antigens. Am J Surg Pathol.1994;18:175-86.

48. Shi C, Huang J, Liu X, Zeng X, Cheng C, Yin Q, et al. Diagnostic significance of hepatitis B viral antigens in patients with glomerulonephritis-associated hepatitis B virus infection. Diagn Microbiol Infect Dis. 2012;72:156-60.

49. Mohammad AJ, Jacobsson LT, Mahr AD, Sturfelt G, Segelmark M. Prevalence of Wegener's granulomatosis, microscopic polyangiitis, polyarteritisnodosa and Churg-Strauss syndrome within a defined population in southern Sweden. Rheumatology. 2007; 46:1329-37.

50. Pagnoux C, Seror R, Henegar C, Mahr A, Cohen P, Le Guern V, et al. Clinical features and outcomes in 348 patients with polyarteritisnodosa: a systematic retrospective study of patients diagnosed between 1963 and 2005 and entered into the French 
Vasculitis Study Group Database. Arthritis Rheum. 2010;62:616-26.

51. Zhang Y, Zhou JH, Yin XL, Wang FY. Treatment of hepatitis B virus-associated glomerulonephritis: a meta-analysis. World $J$ Gastroenterol. 2010;16:770-7.

52. Yi Z, Jie YW, Nan Z. The efficacy of anti-viral therapy on hepatitis B virus-associated glomerulonephritis: A systematic review and meta-analysis. Ann Hepatol.2011;10:165-73.

53. Reddy KR, Beavers KL, Hammond SP, Lim JK, Falck-Ytter YT, American Gastroenterological Association I. American
Gastroenterological Association Institute guideline on the prevention and treatment of hepatitis B virus reactivation during immunosuppressive drug therapy. Gastroenterology. 2015;148:215-9

54. Perrillo RP, Gish R, Falck-Ytter YT. American Gastroenterological Association Institute technical review on prevention and treatment of hepatitis B virus reactivation during immunosuppressive drug therapy. Gastroenterology. 2015;148:221-44. 